\title{
Logical Form and the Vernacular
}

\author{
REINALDO ELUGARDO AND ROBERT J. STAINTON
}

\begin{abstract}
Vernacularism is the view that logical forms are fundamentally assigned to natural language expressions, and are only derivatively assigned to anything else, e.g., propositions, mental representations, expressions of symbolic logic, etc. In this paper, we argue that Vernacularism is not as plausible as it first appears because of nonsentential speech. More specifically, there are argument-premises, meant by speakers of non-sentences, for which no natural language paraphrase is readily available in the language used by the speaker and the hearer. The speaker can intend this proposition and the hearer can recover it (and its logical form). Since they cannot, by hypothesis, be doing this by using a sentence of their shared language, the proposition-meant has its logical form non-derivatively, which falsifies Vernacularism. We conclude the paper with a brief review of the debate on incomplete definite descriptions in which Vernacularism is assumed as a suppressed premise.
\end{abstract}

\section{Introduction}

The overall aim of this paper is to urge that (1) below is not obviously true, and to explain why that is important. ${ }^{1}$

The paper began life as part of the 1998 American Philosophical Association, Central Division panel on Ernest Lepore and Kirk Ludwig's neo-Davidsonian account of logical form. We are grateful to them for their encouragement and questions. It was later presented, in revised form, at Illinois Wesleyan University, in the Cognitive Science Research Seminar at Carleton University, as a three part ciclo de conferencias at the University of Puerto Rico at Mayaguez, and as a panel paper at the 1999 Canadian Philosophical Association Meeting. We are indebted to the audiences at these various spots for very useful questions and suggestions. We are especially indebted to Andrew Botterell for his penetrating and helpful comments on multiple drafts of this paper. We would like to thank the anonymous referee for Mind \& Language for some very helpful comments. Many thanks as well to Kent Bach, Lenny Clapp, Monte Cook, Steven Davis, Bernard Linsky, Randal Marlin, Robert May, Paul Pietroski, and Daniel Stoljar for discussion and comments. Since writing this paper, we came across a paper by Dan Sperber and Deirdre Wilson that dovetails with ours in certain respects, cf. Sperber and Wilson (1998).

Address for correspondence: Reinaldo Elugardo, Department of Philosophy, University of Oklahoma, Norman, Oklahoma 73019-2006, USA.

Email: relugardo@ou.edu

1 Other philosophers have defended the general view that propositions (thoughts, conceptual representations) have their logical forms fundamentally rather than derivatively, cf. Grice (1989), Fodor (1978), Sperber and Wilson (1981). Although we argue for the same thesis in this paper, our main argument differs from theirs in that we argue that the phenomenon of non-sentential speech pose a serious problem for Vernacularists. Julius Moravcsik has argued that natural languages cannot be formally represented in any (possible) system of logic, cf. Moravcsik (1998). To mention just one of his arguments, English generic sentences, e.g. 'The beaver builds dams', cannot be assigned a single logical form that captures all of their entailment relations (Moravcsik (1998, pp. 73-84)). If Moravcsik's general thesis is correct, then no natural language sentence has a logical form (in the sense of having a logical formula that represents its meaning.) But if no natural language sentence has a logical form, then Vernacularism is false since it entails that some do have logical form. In this paper, we grant in our main argument the Vernacularist premise that natural language sentences have a logical form. Hence, even if Moravcsik were wrong about natural languages—and we take no stand on that issue here-we would still have a strong argument against Vernacularism if our argument is cogent.

Mind \& Language, Vol. 16 No. 4 September 2001, pp. 393-424.

(C) Blackwell Publishers Ltd. 2001, 108 Cowley Road, Oxford, OX4 1JF, UK and 350 Main Street, Malden, MA 02148, USA. 
1. Vernacularism: The view that logical forms are fundamentally assigned to expressions of natural language, and are only derivatively assigned to anything else: e.g. propositions, mental states, etc.

We will begin, however, by saying a little about what Vernacularism amounts to-by specifying what, by our lights, it is to have a logical form; and what it is to have one 'fundamentally'. ${ }^{2}$

\section{Preliminaries}

\subsection{Having a Logical Form Fundamentally}

We won't even try to canvass everything philosophers and linguists have intended by 'logical form'. ${ }^{3}$ But to clarify what we mean by it, let us say this:

2. Logical Form: The logical form of $\alpha$ is that in virtue of which agents recognize $\alpha$ 's structural entailment relations.

To have a logical form, then, $\alpha$ must be capable of being true or false (possibly

2 We recognize that, in focusing on what it is to have a logical form, we are dodging the issue of what sort of things logical forms are. Are they concrete, or abstract? Or maybe mental? Are they objects, or are they properties? More specifically, are they expressions (e.g. of some artificial language), or are they patterns-exhibited by natural language sentences, propositions, beliefs, etc.? For present purposes it doesn't much matter what logical forms are. What we care about is when it's correct to say that a thing has a logical form. And, according to our stipulation, as long as something has structural entailment relations, and those are recognizable by agents, then it has a logical form. In which case-and this will be essential in what follows - as long as something can be used as a premise in an argument, it must have a logical form. For, if it is to be used as a premise, the thing must have entailment relations; and those entailments relations must be recognizable to the interlocutors. Some philosophers will deny our claim that if $x$ can be used as a premise in an argument or have entailment relations, then $x$ has a logical form, cf. Moravcsik (1998). We suspect that their arguments against our claim are based on the assumption that the logical form of a thing is some logical formula used to represent its meaning or content. We are not committed to that assumption, cf. $20 \mathrm{ff}$.

3 By 'logical form', we do not mean the linguist's notion of a level of representation (LF) of certain grammatical properties, such as scope and anaphoric relations. Thus, we are not claiming that certain non-linguistic items have their LFs fundamentally. For a discussion on the differences between the logician's notion of logical form and the linguist's notion of LF, see May (1991). 
in context) $;^{4}$ and it must entail things (and must itself be entailed) in virtue of its structure. ${ }^{5}$ These are necessary conditions. One further necessary condition, for having a logical form, is that agents recognize these latter features (i.e. entailment relations) in virtue of the item's logico-structure. As we use this term, the logical form just is that in virtue of which the item exhibits structural entailment relations, and in virtue of which agents are able to recognize said entailment relations. In brief, these necessary conditions for having a logical form are jointly sufficient.

That said, (2) still may not be clear enough. So let us make a few remarks about two of the key concepts that appear therein: namely, recognition and structural entailment relations. By 'recognize', we mean a certain kind of mental competence. Putting aside memory restrictions, life span, etc., our view is that an agent's mental competence can assign entailment relations to sentences, propositions, etc. Indeed, a certain recognition-competence on the part of agents is required for something to have a logical form. By contrast, recognition-performance is unnecessary for a thing's having a logical form. That said, we do rely on an episodic sense of 'recognize' when we treat recognition as a sufficient condition for something's having a logical form. The idea is this: one cannot recognize - on this occasion, as a matter of performance$\varphi$ 's logical form unless one's competence (non-episodic sense) recognizes the logico-structural entailment relations of $\varphi$. Thus, one cannot occurrently assign a logical form to $\varphi$ unless one has the competence to do so; hence occurrently recognizing an item's logical form is ipso facto a sufficient condition for having a logical form. ${ }^{6}$

4 It may be objected that this condition rules out certain things that have logical form but which are incapable of being either true or false, e.g. imperatives, interrogatives, etc. Although we are only discussing the declarative mood in this paper, we can broaden the discussion thus: $\varphi$ has a logical form only if the sentence-radical part of $\varphi$ has satisfaction-conditions, in roughly Tarski's sense. That will allow for imperatives and yes-no interrogatives to have logical forms, since their sentence-radicals stand for propositions, which have truth-conditions and thus have satisfaction-conditions. It will also allow wh-interrogatives to have logical forms since their sentence-radicals, though not capable of being true or false, will be satisfied by sequences since they stand for a propositional function rather than for a proposition. For instance, the sentence-radical of 'Who bought the book?' is something like '[ $\lambda x$ :person $x$ ] ( $x$ bought the book)'. For a defense of this view of wh-interrogatives, see Stainton (1999).

5 The emphasis on an expression's structural formal properties is important. Otherwise, we would have to say, e.g. that it is part of the logical form of every truth-evaluable English sentence that it entails every necessarily true English sentence. In particular, part of the logical form of 'Clinton had an affair' would be that it entail 'Water is $\mathrm{H}_{2} \mathrm{O}$ ' if the latter is a necessary truth. Which is unacceptable. What's more, on our view, it is no part of the logical form of 'Water is $\mathrm{H}_{2} \mathrm{O}$ ', whatever logical form is, that the sentence is a necessary truth: if it is a necessary truth, then it is so in virtue of its semantic content, semantic meaning, or modal facts, but not in virtue of its logical form.

6 Readers who are skeptical of the competence/performance distinction may read our recognition-condition thus: If an agent recognizes (in the performance sense) some of $\varphi$ 's structural entailment relations, then he or she does so (in part) because of $\varphi$ 's logical form. We take that conditional to express a minimally necessary condition for $\varphi$ 's having a logical 
So much for recognition. Now, a not-so-brief note on structural entailment relations. We use 'structural entailments' to include both of what Gareth Evans (1976) calls 'structural semantic entailments' and 'logical entailments'. For instance, 'John is a fat dentist' seems to entail, in virtue of its structure, 'John is fat' and 'John is a dentist'. We are unsure whether this shows that 'John is a tall midget' and 'John is a fat dentist' have a different structure. They may or they may not. Still, both cases differ from cases of 'logical entailments', e.g., 'John is rich and 5 is odd' logically entails 'John is rich' and ' 5 is odd'. (We suspect, in fact, that Evans' distinction between 'structural semantic entailments' and 'logical entailments' is a matter of degree.) But what is common in all three examples is that the entailments hold in virtue of certain structural properties of the sentences. In contrast, 'Shenae knows that fish swim' entails 'Shenae believes that fish swim' but not in virtue of their structural properties. We exclude cases of informal meaning-based entailments from our characterization of logical form. Whenever we speak of 'entailment relations', this is shorthand for relations of structural logical entailment.

If you supposed that only natural language expressions had structure, then it would follow immediately that only they have logical forms, because only they could have their structural entailment relations recognized. In this paper, we don't suppose that natural language expressions are the only things that have structure of the desired kind. We take for granted, for instance, that propositions and mental representations have constituents, and that they are combined together in the right sort of ways.

Which leads to our next assumption, namely that there are logical forms. This isn't a very big assumption. After all, in general, it is not a brute fact about an item that it has the entailment relations that it has. Nor is it a brute fact that items possessing entailment relations are recognized as such. Which is just to say that there is something-maybe some cluster of properties, maybe some relations - in virtue of which the thing has its 'entailment properties', and in virtue of which they are recognized. ${ }^{7}$ Given this, we are pretty sure

form. It doesn't follow, then, that for $\varphi$ to have a logical form, there must be, at some time or other, someone or other, who actually recognizes (in the episodic, performance sense) some of $\varphi$ 's structural entailments. Hence, our account of having a logical form is compatible with the claim that some things have logical form even though it may never be the case that someone or other recognizes (performance sense) its entailment relations. It's also compatible with the claim that $\varphi$ may have a logical form and yet be so structurally complex that no one could ever cognitively grasp $\varphi$ and, thereby, recognize (performance sense) its entailments.

7 One caveat should be made. One might reasonably ask: 'What if there is some kind of thing for which it is a brute fact, about a thing of that kind, that it has the entailment relations it does?' To accommodate such cases, if they exist, we will stipulate that if $\alpha$ 's having the entailment relations it does is a brute fact, then the logical form of $\alpha$ just is being $\alpha$. In such a case, 'that in virtue of which' $\alpha$ has its entailment relations is . . that it is $\alpha$. Thus, to take an example, suppose that the proposition THAT-CLINTON-IS-PRESIDENT is constituted by its entailment relations. In that case, this proposition has its logical form not so much 'in virtue of some cluster of properties/relations, but in virtue of being the proposition THAT- 
that logical forms in our sense exist. Still, pretty sure isn't the same as mortally certain. And, truth be told, we aren't mortally certain that logical forms exist. (Such are the dangers of broadly empirical inquiry.) The thing is, it's possible to doubt that the items which have semantic content-and hence stand in entailment relations-are the very same things which have structure.

To note a couple of examples, if you thought that the only things which could genuinely be attributed content are global states of persons, then, since whole persons clearly don't have compositional syntactic structure-what would that mean?-you might deny that logical forms, as we've defined them, really exist. (Taking this holistic line needn't entail the radical claim that nothing has syntactic structure. It could be that there are linguistic types which have all the structure one could wish. But, one might still suppose, nothing which strictu dictu has content has structure as well.) Or, to consider a rather more plausible view, if you thought that only actions-or uses of sentences, or maybe "what the speaker said'-really stood in entailment relations, you might say: sentences have structure, but they don't stand in entailment relations; and actions have entailment relations, but they don't have syntactic structure. Once again, this would lead to the conclusion that there aren't really any logical forms in our sense. The reason, to repeat, is that it is a necessary condition for having a logical form that the entity entail things in virtue of its structure. So, if the only things that do the entailing don't have structural properties, they don't have logical forms; and since, ex hypothesis, nothing else has entailment properties, nothing else can have a logical form either. Logical forms, farewell.

At this point we could undertake a defense of the idea that there are things which simultaneously have structure and stand in entailment relations. We could do that. But we won't. What we'll do instead is just state that, in this paper, we are assuming that this picture can be made to work. We note, as well, that the Vernacularist shares this assumption with us. Any reader who, unlike us, and unlike the Vernacularist, is convinced that nothing has both structure and entailment relations might as well stop reading.

The next step, now that we've explained (2), is to distinguish items that have logical forms 'fundamentally' from those that have them only 'derivatively'. ${ }^{8}$ The notion is slippery: generally speaking, we think we know

CLINTON-IS-PRESIDENT. Also, we are willing to suppose that it's conceivable that the properties that underlie the having of entailment relations are different from those that underlie their recognition. But we put this possibility aside for present purposes.

8 We are actually somewhat suspicious of the whole 'fundamental/derivative' distinction. So, we are of course hard pressed to give an analysis of it. Nonetheless, there are cases where it is more plausible that something has a logical form only derivatively. In his 'The Thought', Frege gives an example of a painting that may be interpreted as expressing a Thought. The idea is this: the observer must have a sentence provoked by the painting. She then grasps the sense of this sentence and treats the painting as derivatively expressing this sense. It is plausible, then, that paintings don't have logical forms fundamentally, even though someone could use a painting to 'argue' for some claim. The reason is that the observer, who is 'receiving' the argument, must first grasp something with a fundamental logical form. She 
it when we see it, but it isn't easy to analyze. We can say this, however: if, in order to recognize the entailment relations of $\alpha$, an agent must find some other item $\beta$ that has logical form, then $\alpha$ does not have its logical form fundamentally. Rather, $\alpha$ has its logical form derivatively from $\beta$. In contrast, if a hearer can recognize the entailment relations of $\alpha$ without finding any other logical form-bearing item $\beta$, then $\alpha$ has its logical form non-derivatively. Again, this isn't intended as an analysis of ' $\alpha$ gets its logical form from $\beta$ '. But, analysis or no, the psychological test given is, we think, a sure sign of one thing getting, or not getting, its logical form derivatively from another. ${ }^{9}$

Given how we have characterized 'having a logical form fundamentally', our burden is to establish two things. First, there are non-linguistic entities that stand in entailment relations, such that agents recognize those entailment relations in virtue of something about the non-linguistic entities. If we establish this, we will thereby show that logical forms are assigned to things other than expressions of natural language. Second, those non-linguistic things are not understood via the recovery of some linguistic expression that has a logical form. That is, we must make it plausible that a hearer can recognize the entailment relations of such an item without having to find any natural language expression that has that logical form. That would yield the conclusion that things other than expressions of natural language have logical forms nonderivatively. ${ }^{10}$

\subsection{Why Vernacularism is Attractive}

Vernacularism undoubtedly has its adherents. ${ }^{11}$ Some philosophers are attracted to it because they consider propositions (and other abstracta) to be "creatures

is prompted to do this by the painting. But the painting doesn't really have the logical form, except in this watered-down, causal, sense. (The same may be said for other non-linguistic tokens, e.g. mimed performances, sophisticated gestures.) Now the question is, do things other than sentences have logical forms fundamentally? Or, is it the case that every instance of a non-sentential logical form is basically like Frege's painting example? In this paper, we will defend an affirmative answer to the first question and a negative answer to the second.

9 It follows from the way we defined 'having a logical form' that even things which have them 'fundamentally', have them in virtue of something. So having a logical form 'fundamentally' emphatically does not entail having it as a basic feature of the universe. That is not the sense of 'fundamental' at play.

10 Although we will later argue that some propositions have logical form non-derivatively, we do not take ourselves to be arguing that propositions are the only things that have logical form non-derivatively. We are ecumenical about the kinds of things that can have a logical form fundamentally. As far as we argue in this paper, natural language sentences (types and tokens), artificial formulae, propositions, and mental representations can all have non-derivative logical forms. Indeed, there is no reason why two different things, e.g. a proposition and a sentence, can't have the same logical form non-derivatively from each other and from anything else.

11 We are hard pressed to find anyone who explicitly holds and defends Vernacularism in the literature. Peter Geach and Wilfrid Sellars come close, cf. Geach (1957) and Sellars (1963). According to them, the functional/conceptual role of a thought, which constitutes its structural formal properties, is modeled on the functional/conceptual role of its natural language 
of darkness': propositions, it is said, have no clear identity-conditions, they don't fit nicely with a naturalistic view of the world, etc., cf. Quine (1979). Sentences, on the other hand, are empirically accessible (at least their tokens are), and they have somewhat clear identity-conditions. Besides, even philosophers who are comfortable positing abstract propositions may hold that human beings can only grasp propositions via sentences. Either way, goes this line of thought, if anything has a logical form par excellence and fundamentally, it's not abstract propositions-it's sentences. Of course this alone doesn't yield Vernacularism: one could feel an aversion to propositions, while taking mental representations to be perfectly respectable, even as fundamental bearers of logical form-as does Fodor (1975) and Fodor (1978). But some philosophers are hostile both to abstract propositions and to inner mental states, except in so far as the latter are understood in terms of, for instance, dispositions to utter public language sentences (Carnap 1967) — or possibly in terms of 'inner speech' (Geach 1957). If that is one's view, it simply won't do to countenance mental representations and/or propositions, which have logical forms, such that no natural language sentence endows that logical form. Hence Vernacularism.

Or again, suppose you find deflationary accounts of content plausible, cf. Schiffer (1994). You might maintain, for instance, that contents are simply linguistic posits, which enter into language by 'something-from-nothing' transformations of the following sort:

\section{3. 'Anita lives in Ottawa' $\Rightarrow$ 'The proposition that Anita lives is Ottawa is true'.}

\footnotetext{
sentence-analogue. Since the functional/conceptual role of a thought/sentence will include its inferential/entailment connections to other thoughts/sentences, an object-of-belief that has the same functional/conceptual role as its counterpart-sentence (in a natural language $L$ ) will also have the same logical form as its linguistic counterpart. On the other hand, it is unclear whether Geach and Sellars also hold that, for each (possible) thought-type, there must also be a unique natural language sentence-type from which it derives its logical form. If they don't hold this, then they are not committed to Vernacularism as we have defined it. Some philosophers hold the strong conceptual thesis that having a natural language is both logically necessary and sufficient for having any thoughts, e.g. Davidson (1975) and McDowell (1994). Others hold the weaker, empirical, thesis that some thoughts are the outputs of a biologically-determined language module whose inputs are natural language lexical items, cf. Carruthers (1996) and Carruthers (1998). Neither thesis directly entails Vernacularism, although Carruthers' view comes close. A closely related position is Jerrold J. Katz's 'Principle of Effability': 'Each proposition (thought) is expressible by some sentence in every natural language' (Katz 1981, p. 226). According to Katz, the principle implies that 'the semantic structure of natural languages is complete with respect to the full range of objects to which laws of logic apply and that the expressive structure is complete with respect to the stock of senses semantic structure supplies' (Katz 1981, p. 239ff). That isn't quite the same as Vernacularism but it comes very close. In any case, we will argue below that some philosophers tacitly hold Vernacularism, which is enough to take it seriously even if no one ever explicitly endorsed it.
} 
4. 'Anita believes that Chrétien smokes' $\Rightarrow$ 'Anita believes the proposition Chrétien smokes'.

Taking this line, you might well insist that propositions/belief-contents are real enough, but maintain all the while that they pack no ontological punch. Of course, if propositions/belief-contents are just 'deflationary shadows of sentences', then surely there won't be propositions (or contents) without a corresponding sentence. And, once again, Vernacularism will strike one as congenial. $^{12}$

In sum, certain philosophers will be tempted by the idea that, if abstract propositions or inner mental states have logical form at all, we should understand this in terms of the sentences that express them having that logical form. Indeed, the story would go, we are only able to grasp 'the logical form' of the non-linguistic entities by finding an appropriate linguistic entity. So that such non-linguistic things, if they have logical forms at all, do so only derivatively. That just is Vernacularism.

Vernacularism may have its attractions, but it doesn't come for free: it has broadly empirical consequences that can lead one to doubt its ultimate plausibility. Of crucial interest to us, Vernacularism rules out the possibility of objects-of-belief (e.g., propositions meant by speakers), for which no precise natural language encoding is found by the hearer. It is this aspect of Vernacularism, i.e. the conflict between it and the existence of objects-of-belief that have logical forms non-derivatively, that will be our primary concern.

\subsection{The Game Plan (and some Underlying Issues)}

We conclude this introductory section by sketching our 'game plan' — and by noting some issues that will lie just below the surface in the discussion ahead. We hope this will clarify our motivation in discussing Vernacularism.

The most fundamental background concern will be the relationship between thought and talk. We of course do not take what follows to establish that, for example, thought is something other than inner speech. But we hope that our discussion of Vernacularism contributes to on-going debates in this area. Also closely tied to what follows are debates between proponents of the indeterminacy of content and staunch realists about the mental and/or about propositions: specifically, much of what follows is plausible only given the assumption of content-realism. Some will take this as an argument, from the best explanation, for content-realism: 'Look what we can explain by positing language-independent mental representations/propositions!' Others will complain that a central question has been begged. Be that as it may, we want explicitly to flag that such issues are at play. Equally at play, especially in the

12 Deflationary accounts of belief contents may be found in Barber (1997,1998), and Schiffer (1994, 1996, 1997). 
final section, will be the distinction between perceiving an object or a property, partly in virtue of its presence in the environment, and thinking about the object/property via tokening some linguistic description of it. In part, we maintain, Vernacularism fails because objects/properties can be thought about in virtue of being in the environment, not solely in virtue of satisfying some natural language description running through the mind of the thinker. Curiously, this last point has a lot to do with the nature of ellipsis: specifically, the contrast between drawing attention to things, versus implicitly/elliptically drawing attention to words-for-things; and it thereby highlights issues about the boundaries between syntax and semantics and between semantics and pragmatics.

With those cryptic remarks, we now introduce the game plan. Our discussion of Vernacularism has two parts. First, we argue that Vernacularism is not obviously true. That is, it isn't at all clear that everything that has a logical form either is a natural language sentence, or has its logical form derivatively from some natural language sentence. We will argue that speakers can mean things which have logical forms, but do not have those logical forms 'endowed upon' them by the recognition of a natural language expression. Second, we support our claim that this is important by giving one example in which Vernacularism is assumed, namely debates about Bertrand Russell's Theory of Descriptions.

\section{Logical Form and Speaker's Meaning}

Our question can be divided into two sub-questions:

5. a. Are there things, other than natural language expressions, which have logical forms?

b. Are there things of this kind which have their logical forms fundamentally?

We are now going to mount an argument-not, admittedly, an airtight demonstration - that one should answer 'yes' to both questions. We will introduce a linguistic phenomenon that shows that speakers mean, and hearers recover, things that have logical forms, which are not themselves natural language expressions. That yields a 'yes' to (5a). Our example is also one in which such logical forms are not shared by any natural language sentence employed by the hearer. ${ }^{13}$ That yields a 'yes' to (5b) as well. Given an affirmative answer to both, Vernacularism is ipso facto false.

13 That word 'available' will be important. To anticipate a little, we don't mean to claim that there is no possible human language in which a sentence, sharing the logical form of the meant-proposition, exists. Who knows what riches possible languages might yield. All we claim, and all we need to claim, is that there are cases in which propositions are meant, and understood, without the psychological processing of a sentence that allows the agent to assign to the proposition a logical form. 
The phenomenon we have in mind is one in which a speaker produces an ordinary word or phrase, in an argument, and thereby communicates a full proposition. Because the thing-meant is not itself a sentence, but is instead a proposition, one recognizably used in an argument, this thing-meant forces a positive answer to (5a), or so we will shortly argue. We then argue that the hearer need not assign the logical form to the proposition-meant by recovering some item of language which encodes the proposition. He can do so 'directly', as it were.

There are multiple ways in which one could argue for this latter conclusion. An experimental psychologist might do studies of reaction times, priming effects, and so on, in cases of non-sentential speech; a (presumably future) neurolinguist might bring to bear PET-scan studies of brain activity, clinical case studies of bizarre aphasias, or who knows what. Either route might imaginably uncover evidence that logical forms are assigned, in cases of non-sentential communication, without the aid of mediating full sentences. In a more familiar vein, a corpus linguist might provide multiple examples of attested speech, and argue that in many actually observed cases the hearer did not recover any sentence. (Some initial steps within the latter approach were taken in Stainton (1989/92) and Stainton (1990/91.) We would be keen to see the results of such work. But our methodology will be more akin to that of generative grammar and philosophy of language. That is, we will imagine a dialogue situation, and we will then mine intuitions about what, plausibly, is actually going on in the imagined situation. ${ }^{14}$ Our conclusion will be that the hearer in the imagined situation does not recover a sentence when he understands the non-sentential speaker. In so far as the imagined situation really is plausible, it supports the conclusion that an agent can recover a thing-meant which has a logical form, and which is not a sentence, such that the thing-meant has its logical form fundamentally. (The transition is: what does happen in a possible situation is something that can happen in the actual world.) It is this possibility which makes (1) questionable. Since the argument hinges on the plausibility of the situation described, we then consider many arguments designed to show that our description is actually implausible.

\subsection{The Non-Sentential Example}

Here, then, is the imaginary case. A discussion has taken place between Alice and Bruce in which Bruce takes the position that there are not really any colored objects. A day or so later, Alice meets Bruce. Having just read G.E. Moore, she offers the following counter-argument. She picks up a red pen, and says 'Red. Right?'. Bruce, guileless fellow that he is, happily agrees. Alice

14 We recognize that there is something odd about this methodology of imagining a case, and then asking what is 'really' happening in the case described. But it would take us too far afield to justify the overall methodology. 
continues, 'Red things are colored things. Right?' Bruce nods. At which point, Alice springs her trap: 'So Bruce, there is at least one colored thing. This thing.'

Here is what we wish to stress about the example. First, Alice is making an argument: She communicates propositions, which are premises in the argument; and these premises do indeed have implications with respect to the existence of colored things. And, of course, Bruce recognizes those implications. But premises that fit together into an argument, and are understood to do so, cannot help but have logical forms. So, what Alice communicated at each step had a logical form. (Whether she asserts the proposition, or merely implicates it, is not important for present purposes. What is crucial is that she communicates something that is correctly recognized to have structural entailments.) Second, given the lapse of time, it will not be clear to Bruce or to Alice what words were employed during their first exchange, although they both recall the general topic of discussion. The particular words or phrases that were produced will not be immediately available to them during their second exchange. In which case, Bruce will not, during the second meeting, employ those specific expressions in interpreting what Alice meant. Notice, also, that all the evidence that Bruce actually uses is what we described. He does not need to ask Alice any questions, access further evidence that would be available to a third-party, etc. Nor does he need to wait until her argument is done to know what she has communicated with 'Red'. Finally, let us add that Bruce cannot say 'which natural language sentence he used' to understand Alice. Plausibly, then, Bruce understands her just on the basis of her utterance of the word 'red' and the fact that she held up a red pen.

Our contention is that, in this imagined case, Bruce did not recover any sentence in understanding Alice. What he did, instead, was to understand the predicate 'red', and apply its meaning to the salient object, the pen in Alice's hand. Doing this, he came to grasp a proposition. And that proposition had a logical form. If this description of what Bruce did is plausible, then it's also plausible that a real agent can in fact recover something that isn't a natural language expression, yet which has a logical form non-derivatively. Precisely because, in the described possible situation, this is just what Bruce does.

\subsection{Resisting the Non-Sentential Example}

The 'Red' example given above is highly controversial. The Vernacularist can make many moves to diffuse its force. In this section we consider a host of these, each of which ultimately amounts to a claim that our description of the case is mistaken. Not to hold you in too much suspense: we find that none of these means of resistance is very effective. To keep things as straight as possible, we divide the objections into four main varieties: those which deny that the thing-meant has a logical form; those which deny that the thingmeant is something other than a linguistic expression; those which deny that it has a logical form non-derivatively; and those which appeal to the primacy of sentences. That is, we divide objectors into: one group which insists that 
(5b) can still be answered 'no'; two sub-groups which insist that (5a) can still be answered 'no'; and those who, these questions aside, think there is something fundamentally wrong with the example itself. The first three of these objections can be further sub-divided according to the following taxonomy:

\section{OBJECTIONS TO THE IMAGINED CASE}

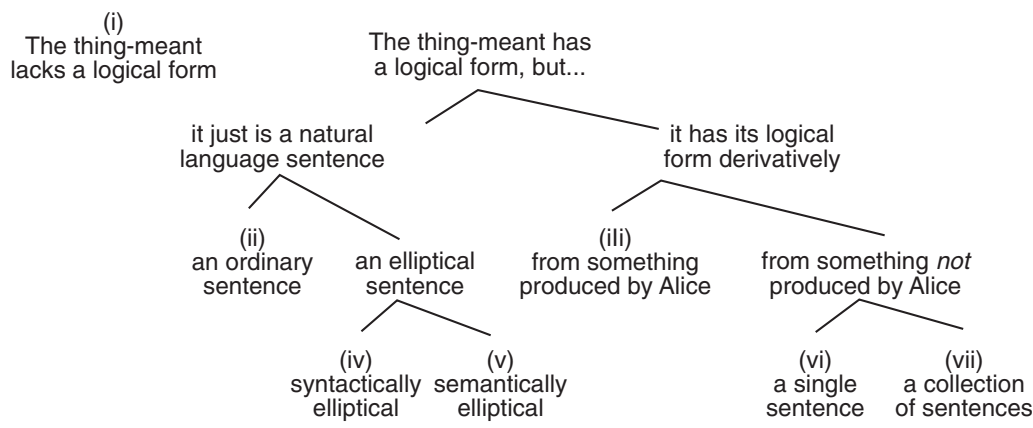

\section{Objection (1): The Thing Recovered Just Is A Sentence.}

One's first reaction to the example might be that Bruce clearly did recover an ordinary sentence when he understood what Alice meant. Indeed, it might seem perfectly obvious what the sentence was: 'This thing is red'. But why include the word 'thing' as opposed to 'object' or 'doohickey'? Is it so clear that Bruce definitely recovered the former and did not recover either of the latter? Fair enough, one might say. It's not (6) but (7) that Bruce obviously must have recovered:

6. This thing is red.

7. This is red.

But is (7) any better? As far as we can tell, nothing adequately justifies the claim that Bruce obviously mentally tokened a bare English demonstrative rather than a complex demonstrative or a definite description. For instance, nothing rules out 'The pen in my hand is red' as an equally good (or better, equally bad) candidate. Moreover, why must the verb be 'be'? Why not 'instantiates' or 'exemplifies' or 'embodies'? ${ }^{15}$ The basic difficulty is this: It

15 Robert May suggested to us that there could be minimal completions of non-sentential expressions, and that this would justify choosing 'This is red'. Applied to the example at hand, the idea is that the minimal way of getting a sentence from [AP red] is (a) to embed this phrase in a VP headed by a light verb, thereby creating, for example, [VP is [AP red]]; and (b) to concatenate the result with a minimal demonstrative, for instance [DP this]. On this view, then, while the speaker produces a non-sentence, what the hearer recovers is nevertheless a sentence. And it is this sentence which fundamentally has a logical form. We 
seems to us, as it would likely seem to anyone who wasn't antecedently assuming something like Vernacularism, that the proposition which Alice communicated is essentially less precise than any fully sentential paraphrase of it. Just as none of 'vermilion', 'crimson', 'maroon' or 'scarlet' precisely captures the meaning of 'red', so no available sentence precisely and uniquely expresses what Alice meant. Hence it really is plausible that Bruce understood Alice without recovering an ordinary sentence-because otherwise it should be easy to say what sentence it was that Bruce recovered. Indeed, if Bruce had recovered a sentence, it would be easy for him to say which sentence it was. And yet it surely cannot be denied that Bruce may be perfectly unable to pick out 'the' sentence he recovered.

Putting (ii) aside, then, the next natural thought is that Alice uttered, and Bruce recovered, an elliptical sentence: not 'This thing is red' or 'This is red' or 'The pen in my hand is red', but rather a non-ordinary sentence which is pronounced red. This proposal can be understand in one of two ways:

8. Two Ellipsis Hypotheses.

(a) 'Red' is syntactically a single word, but one which expresses a proposition in a context. (That is, 'Red' is a 'one word sentence', semantically distinct from the ordinary word 'red': whereas the latter is of type $<\mathrm{e}, \mathrm{t}\rangle$, the former is of type $<\mathrm{t}\rangle$.)

(b) 'Red' is not really a word at all. Rather, it is syntactically an elliptical sentence-one which, like syntactic sentences generally, expresses a proposition in context.

Option (8a), which Stainton (1995) has called 'the Semantic Ellipsis Hypothesis', violates the semanticist's version of Occam's Razor: Do not multiply ambiguities beyond necessity. For, in order for the sound red to sometimes express a proposition in context, the sound type must have at least two meanings, namely, the property RED (which it contributes, for example, in 'That pen is red') and the proposition that the contextually salient object is red (which it purportedly contributes in the Alice-Bruce dispute above). ${ }^{16}$ But

grant that this proposal is initially plausible for this case, taken in isolation. But we do not believe that minimal completions are generally available. For instance, what would be the minimal completion of 'A pint of English bitter', understood as uttered to a bartender? It clearly isn't 'This is a pint of English bitter'. But is it 'I want a pint of English bitter', 'Give me a pint of English bitter', 'I'd like a pint of English bitter', or something else again? Which of these is minimal?

16 We of course distinguish the case in which a speaker means that $P$ by using a sentence which, even in the context, does not mean $P$, from the case in which a speaker means that $P$ by using a sentence that does mean $P$ in the context. On our view, the 'Red' example is like the first case but is unlike the second. For, Alice did mean a proposition-but her word, even given a context, does not semantically mean a proposition. In support of that claim, we distinguish between type meaning, literal token meaning, and speaker meaning, where literal token meaning is determined by type meaning plus some contextual elements explicitly anticipated in the rules of use for the expression type. Given this three-fold distinc- 
the multiplication of meanings doesn't stop there. For 'Red' can also be used, on its own, to communicate the proposition that red is a 'warm' color. This proposition has a different form from the one Alice communicated. After all, Alice communicated a first-order proposition, predicating redness of an object, while this is a second-order predication, applying WARM COLOR to redness. 'Red' can also be used to communicate an identity statement between properties (e.g. Red = John's favorite color), a universally quantified statement (e.g. every pen hereabouts is red), etc. But no univocal expression can express an identity statement, a quantified statement, a first and a second order predication, etc. (That is, no univocal expression can be type-synonymous with all of: 'red', 'This is red', 'Red has this', 'Red is identical to this', etc.) Hence, if it were the one-word sentence 'Red' which Bruce recovered, the sound red would have to be multiply ambiguous.

Now, ambiguities do happen. But one shouldn't posit them unnecessarily especially when what's at stake is the multiple ambiguity of essentially every phrase in the language. And that is, indeed, at stake because, as Barton (1991) argues, any phrase whatever can be used in isolation, to perform a speech act. Consider 'Another glass of that delicious German beer', 'Nice car', 'Three letters from Spain', and so on. However, the ambiguity posited here is unnecessary, because pragmatics can easily fill the gap between the content of the word uttered (i.e. a property) and the content of the thing communicated (i.e. a proposition). After all, the speaker couldn't possibly be communicating a property-what would that amount to? So the hearer, to preserve the assumption (in familiar Gricean fashion) that the speaker is cooperating, must look for a proposition communicated. She could find such a proposition directly, by applying redness to the salient pen.

So much, then, for the first ellipsis hypothesis. The second option can be shown false on empirical grounds: 'Red' is not overtly headed by an inflectional element; nor is it the least bit plausible, given what linguists know about syntactic ellipsis, that 'Red' has a covert subject or a covert INFL node. In support of this second claim, we note two other salient facts. First, syntactically elliptical sentences cannot be used to initiate discourse, except under very special circumstances. For instance, one cannot, without awkwardness, walk into a room and say 'Alex does too'. In contrast, 'Red' and other bare phrases can occur as freely in discourse initial position as non-elliptical sentences: the discourse initial use of 'Red' is no more restricted than the use of 'This is red'; in contrast, its discourse initial use is much less restricted than the use of 'This does too'. Also, syntactic sentences (including syntactically elliptical sentences) can license sluicing and other genuinely elliptical constructions in ways that a

tion, the question is whether the type meaning of 'Red', is the same as the type meaning of 'This is red'. If it is not, then the literal meaning of utterances of the two, holding context fixed, cannot be the same. 
non-sentence (like 'Red') cannot. Consider in this regard the contrast between the (A) and (B) discourses:

Sluicing post-sentence and post-non-sentence

(A) Peter: Who is at the door?

Ernie: The man from Paris.

Rob: I wonder why.

(B) Peter: The man from Paris!

Rob: ${ }^{\star}$ I wonder why.

In (A), the sound the man from Paris is plausibly paired with a syntactic sentence, occurring as it does in reply to a wh-interrogative. That is, though Ernie produces only the sound the man from Paris, the sentence he produced could well be (something like) [IP [DP The man from Paris][I, is at the door]]. And here, 'I wonder why' is fine. By contrast, in (B), the sound the man from Paris is plausibly taken to correspond simply to the phrase [DP The man from Paris]. The sluicing construction is not licensed here precisely because, in the (B) case, what was produced was not a sentence - not even an elliptical sentenceand sluicing demands a sentence.

In sum, 'Red' is not an elliptical sentence, at least not in any sense that lends comfort to Vernacularism. ${ }^{17}$ Any feeling that 'Red' must be elliptical derives, we suspect, from the indisputable fact that what the speaker means by it is a proposition. But given the distinction between semantics and pragmatics, this by no means establishes that 'Red' has the syntax or the semantics of, for example, 'This object is red'. In which case, 'the elliptical sentence' cannot serve as the linguistic expression that Bruce recovered.

\section{Objection (2): There is a Logical Form, but it is Derivative}

So far we have responded to objections (ii), (iv) and (v) in the previously noted taxonomy. We turn now to a series objections according to which the thing-meant, which Bruce recovers, is not itself a sentence, but it nevertheless 'gets its logical form' from a sentence. Assuming the logical form of what Alice meant is derivative on a natural language expression, there are only two options for the 'source' expression, recovered by Bruce. Either it is some expression that Alice did not produce, or it is an expression that she did produce.

We can rapidly deal with the proposal that Bruce recovers a proposition, but assigns it a logical form by means of (also) recovering the linguistic expression that Alice produced. This could only work if Alice produced something which encoded a proposition. That is, if she produced something which

17 This isn't the first paper to make hay of non-sentential speech. For more on the pragmatics of non-sentential speech, see Stainton (1994). On semantic ellipsis and syntactic ellipsis, see Stainton (1995) and Stainton (1997) respectively. A general overview, and an application to quantifier phrases, can be found in Stainton (1998). 
was not an ordinary word or phrase, but was instead an elliptical sentence. But that hypothesis immediately runs into the just noted objections.

Well, but, isn't there one more sense in which the logical form could derive from 'the thing used by Alice'? Here is what we have in mind. It's quite clear that there is such a thing as Alice's speech act. What's more, at least in a broad sense, that speech act is something linguistic. And, it has exactly the same content as what Alice meant. So why can't the logical form of the thing-meant come from it? True enough, Vernacularism as stated would strictly speaking be false, since there would still be no natural language expression from which the proposition-meant gets its logical form. Nevertheless, use of language would still be fundamental in accounts of logical form. And that is surely the deep issue here.

The point is well taken. But we think the following reply is compelling. In order for an entity $\beta$ to be that from which some item $\alpha$ derives its logical form, $\beta$ must itself have a logical form. After all, the agent assigns a logical form to $\alpha$ by recognizing the logical form of $\beta$. However, to have a logical form, an entity must have constituent structure. That was part of the definition. And-here comes the punch line-speech acts do not have constituent structure. Of course the thing uttered, in the speech act, clearly does have syntactic structure. But the act itself does not. Unless, of course, what is meant by 'the syntax of the speech act' is just, 'the syntax of the thing uttered'. Then one could speak of the syntactic structure of the speech act. The problem is, we have already established that the expression uttered cannot be what gives the proposition-meant its logical form, because the thing uttered is a 'plainold word'. So, on this understanding, 'the structure of the speech act' cannot do the job either. In sum: in one sense, speech acts don't have structural entailments at all; in another they do, but they are inherited directly from the structure of the expression used. Either way, the speech act cannot be that from which the thing-meant derives its logical form. We move, then, to the hypothesis that the logical form is derivative on something not used by Alice.

We have already noticed one reason why we need not take the logical form to be derivative on any one specific sentence of English: each such sentence is too precise to be the one which Bruce 'obviously used'. Alice did not mean 'This pen is red' as opposed to 'This thing is red', any more than she 'really' meant vermillion by 'red'. One might say, in reply: There is a sentence all right - it's just hard to figure out which one it is. But, once again, if Vernacularism were true, why should it be hard? For what Alice meant must 'get its logical form' from this unique sentence in the minimal sense: Bruce is purportedly only able to recognize the entailment relations etc. of the thing meant, by finding a sentence which expresses the thing meant, and then recognizing the structural entailment relations of that sentence. He does not assign a logical form directly to the proposition-meant. Taken this way, propositions-meant do not have logical forms fundamentally. But how can one recognize the 
proposition-meant in this manner, and yet find it hard to state the specific sentence which one supposedly had to recover in order to find the logical form? ${ }^{18}$ Why, when questioned, doesn't Bruce know that he emphatically did not recover the sentence 'This pen is red', but instead recovered 'This is red'? Why is he any less certain than if Alice had simply produced a full sentence? After all, in each case, Bruce supposedly recovers the sentence. The right thing to say, in answer to all of these rhetorical questions, is that the proposition has a logical form that we recognize, and that it does not get this logical form derivatively.

Nor, turning to (vii), will it do to maintain that several sentences taken collectively determine the logical form of the thing-meant. For this gets the explanatory order wrong. Surely it's because of the nature of the proposition communicated that all of (9) count as close paraphrases, and not vice versa.

9. a. This pen is red.

b. This thing in my hand is red.

c. This is red.

d. The pen here is red.

To give an analogy, there are two ways of understanding the location of the bull's-eye vis à vis an arrow. One might say, 'The bull's-eye is located just here because this arrow came very close, that arrow missed by a few inches, and that arrow was nowhere near'. One might also say: 'This arrow came very close because the bull's-eye is just here, and the arrow struck just there'. In the case of the bull's-eye, it's clear that the former gets the order of explanation wrong: the bull's-eye does not come to have its location because such-andsuch an arrow missed. Now consider: in virtue of what is 'This thing is red' a quite good paraphrase of what Alice meant, whereas 'This doohickey exhibits red' isn't very good, and 'My plane is late' is nowhere near? Is 'the target' determined by which things come close and which are far away? Or is the closeness of the paraphrase determined by where the target is? We take the latter line. (And, we believe, only someone antecedently in the grip of Vernacularism would insist otherwise.) In which case, the paraphrases are not prior to-do not determine- the thing-meant.

\section{Objection (3): There is No Logical Form Bearing Thing-Meant}

We have argued that the thing-meant is not itself a sentence, and that it does

18 It could be that the explanation is that the recognition/recovery process is a subconcious process. Maybe so. But Vernacularists cannot appeal to such an explanation in response to our argument. For, they restrict the relevant mental states involved in communication to public-language things, e.g. dispositions to utter, affirm, deny, etc., public natural language sentences. On their view, positing tacit mental states, which cannot be analyzed as public linguistic dispositions, is out of the question. 
not have its logical form derivatively. If it has one at all, it has it fundamentally. At this point, one might think that it was a mistake to have agreed that there is a proposition-meant that has a logical form. Maybe the thing-meant is not even propositional. Or, it is a proposition but it is too vague to have a logical form. The phenomenon, so construed, would not be: 'There is definite proposition for which we cannot find a sentence available to the hearer'. On the contrary, there is no proposition-meant to be 'captured' at all. We have arrived at objection (i).

Of course there certainly is the illusion of the thing-meant being a proposition with a logical form. Without question there is an argument here, whose premises fit together in a way that supports the conclusion. The explanation of this illusion might run as follows. There are many things that correspond to the thing-meant, each of which has a logical form. For instance, all of the sentences in the cluster (9), noted above, have logical forms; and all of them are rough paraphrases of what was meant; moreover, any number of them could combine with the sentence 'Red things are colored things', thereby supporting something like Alice's conclusion. (Whether the resulting reconstructed argument was valid solely in virtue of form would depend upon which of 'This thing is red', 'This instantiates red', etc. is selected.) In sum, there is something meant by Alice, and there is at least one thing that has a logical form, but they aren't the same thing.

How to respond? Well, there are things which quite precisely capture the logical form of the thing-meant. None, however, is an English sentence plausibly recovered by Bruce. Here is one example, which is an expression in an artificial logical language:

10. $\operatorname{Red}\left(x_{3}\right)$.

(10) is an open sentence. It is the sort of thing that combines with either a bare quantifier (e.g. ' $[\forall x]^{\prime}$ ) or a quantifier phrase (e.g. ' $[\exists x$ : pen $(x)]$ ') to form a closed sentence. When the variable is free, however, we stipulate that it refers to the third element of the given variable assignment. Spelling this out a little, we might stipulate the following sequence as a variable assignment:

11. <The moon, Noam Chomsky, the demonstrated pen, Jerry Fodor, the sun, ...>

(To simplify, let's agree that 'how the object is presented', i.e. its mode of presentation, is unimportant here.) Given this assignment, (10) expresses precisely what Alice meant: the open sentence $\operatorname{Red}\left(x_{3}\right)$ ' is true relative to this sequence if and only if the third element of that sequence is red. Given sequence (11), the whole is indeed true, because the demonstrated pen is red; (10), given, (11), pretty clearly has a logical form. So, if the logical form of (10)-given-(11) is the same as that of the proposition which Alice meant, then 
what Alice meant has a logical form. The generalization here is: if $x$ has the same logical form as $y$ does, and $y$ has a logical form, then patently $x$ has a logical form. (It's also worth noting that, taken in abstraction from any sequence, ' $\operatorname{Red}\left(x_{3}\right)$ ' doesn't have the same logical form as the propositionmeant, since the latter has a truth-value (which is, of course, contextindependent), while the former does not. But given a sequence, they share a logical form. That said, (10)-given-(11) has a logical form; and it has the same logical form as the proposition-meant. So the proposition-meant has a logical form. ${ }^{19}$ )

The objection, recall, went like this. It was a mistake to have agreed that there is a proposition-meant that has a logical form. To which we replied: There must be a proposition-meant with a logical form because (10)-given(11) has the same logical form as what Alice meant. Two points about our response should be emphasized. First, treating (10)-under-(11) as sharing the logical form of the thing-meant does not immediately grant victory to Vernacularism because (10) is not a natural language sentence. Second, quite obviously, if a thing's logical form can be accurately described, then it must have a logical form. What we've just done, by introducing ' $\operatorname{red}\left(x_{3}\right)$ ', is describe what Alice meant, including describing its logical form. Thus, there is something which Alice meant and it has a logical form.

One might worry that the existence of (10) makes our rejection of Vernacularism less interesting. After all, the really interesting claim is that objects-of-belief have their logical forms fundamentally. But, one might say, the proposition-meant by Alice-which, notice, is the object of various attitudes by both speaker and hearer-can have its logical form 'endowed' by (10). Hence, the object-of-belief still ends up having its logical form derivatively-though admittedly, not derivatively on a natural language sentence. We believe, however, that this worry can be easily diffused. The key move goes like this: Bruce, we can safely agree, does not know the artificial logical language that we just introduced. He doesn't know about free variables, sequences, etc. Hence, his grasp of the proposition-meant, and his apprehension of its logical form, cannot be via his recognition that, for example, the proposition-meant shares the same logical form as (10)-under-assignment-(11). In which case, it cannot be that (10)-given-(11) endows the proposition-meant with its logical form. In brief, for the proposition-meant to 'get its logical form' from something else, it must be something available to speaker and hearer

19 We would like to prevent a possible misunderstanding of our argument. We have argued that if there is such a thing as a logical formula that has the same logical form as $x$, then surely $x$ has a logical form. Our conclusion is not based on the assumption that the logical formula is the logical form of $x$. If it were based on that, then we might be accused of conflating the logical form of $x$ and the logical formula used to represent $x$ 's meaning. Our argument does not, however, rest on any such confusion. Rather, it proceeds from the valid general principle that if $y$ has the same $\phi$ as $z$, and if $y$ has a $\phi$, then $z$ has a $\phi$. 
which can do the job. Our reply to the worry, then, is that (10) simply is not available to Bruce. $^{20}$

A rather different worry about our response in this section is the following. It might be suggested that appealing to (10), in describing the logical form of the proposition that Alice meant by 'Red', leads to a pragmatic paradox of some sort. It better be possible to explain, in natural language, what (10) means. For instance, one needs to describe the artificial logical language, and how variable assignment works for that language, etc. Yet if one can do that, runs the objection, then there are English sentences that express what Alice meant. And maybe they are the ones used by Bruce. In a nutshell, either one can say, in English, what Alice meant or one can't. If one can, then Vernacularism is true. If one cannot, then there is no reason to believe that a proposition really was meant. Our rejoinder is that there is an equivocation on 'there are English sentences that express what Alice meant'. We are not claiming that it's impossible to describe what Alice meant, using English. Indeed, we have been at pains to characterize what she did (and did not) mean. Nor do we maintain that Bruce would be at a loss to describe, in complete sentences, what he understood. Our contention, rather, is that there is no unique sentence of English which Bruce used to understand Alice. That is, there is no available sentence of English that is a 'direct translation' of her thought - though what she meant can be described by us, and by Bruce. ${ }^{21}$ In contrast, the content of (10) does capture, given the sequence, just what was communicated: i.e. given the sequence, (10) encodes the proposition that Alice communicated. In which case, what Alice meant has a logical form, and, as we argued above, it is one that cannot be assigned derivatively in terms of the logical form of an available natural language expression.

20 Another closely related clarification should be made. We don't wish to commit ourselves to the (very strong) claim that no sentence of any natural language could encode what Alice meant (cf. Sperber and Wilson, 1981). Maybe there are sentences of Russian, or of Urdu, or of who-knows-what, which do express the very proposition-meant. But even if that were the case, it wouldn't establish that the thing-meant gets its logical form, derivatively, from a natural language sentence. For it cannot be the case that monolingual speakers of English, who perfectly well understand the proposition communicated, do so by recovering a non-English natural language sentence, finding its logical form, and then assigning that logical form to the proposition meant. Rather, monolingual Anglophones must grasp the logical form of the proposition-meant, without grasping any natural language sentence sharing that logical form. That is, here again, there is no available natural language sentence to endow the proposition-meant with its logical form. Which surely means that the proposition must have a logical form, independently of any sentence whatever. (The first worry, about whether an artificial language sentence might endow the logical form, was raised by David Anderson. The second worry, about whether a sentence in some other natural language might share the logical form, was noted by Ernest Lepore and Kirk Ludwig. We would like to thank all three for raising these points.)

21 See Bar-On, 1994, for a related distinction applied to 'There is a translation'. She notes that 'There is no English translation for sentence $S$ ' does not entail 'We cannot describe $S$ 's meaning in English'. 


\section{Objection (4): The 'Context Principle' Objection}

We have sometimes heard the following sort of complaint about the 'Red' example:

As Frege stressed long ago, only sentences have meaning in isolation. Later, Dummett and Wittgenstein rightly added that only sentences can be used to make a move in the language game. ${ }^{22}$ Given this, there must be something amiss with the Red example.

What this complaint highlights is that there seems to be a tension between our example and both Frege's (1884) notorious 'Context Principle' and the Wittgenstein-Dummett dictum about use. Given that both are very widely assumed, we had better say something about how these claims intersect with our views.

The first point we need to make is that there are at least three ways of understanding 'sentence'. These are:

\section{Three Senses of 'Sentence'}

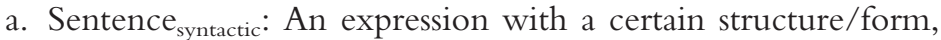

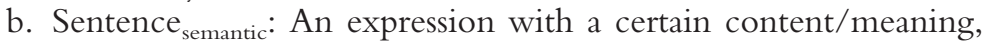

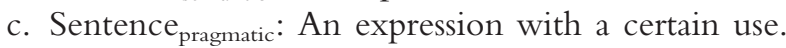

An example of a syntactic characterization of sentence can be found in Chomsky's Government and Binding Theory. There, a sentence syntactic $_{\text {just is a (maximal }}$ projection) phrase structure whose grammatical head is an INFL node-where INFL nodes contain tense (e.g., present, past, future) and agreement (i.e., person, gender, number) markers. A more traditional syntactic characterization

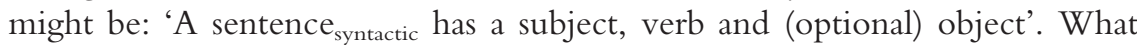
both of these have in common should be clear enough: they categorize expressions by the kinds of syntactic elements that they are built from.

What about (12b)? Here, one might say: 'A sentence semantic is an element which expresses a proposition'. Of course this will need to be refined, to cover sentences which are context sensitive. Better would be: 'A sentence semantic $_{\text {is }}$ an expression, tokens of which, once reference has been assigned to all context sensitive elements, express propositions'. For present purposes it is enough to say, in the notation of Montague grammar, that sentences, in this semantic sense, are of type $\langle\mathrm{t}\rangle$. (Notice that this divide, between syntactic-sentences and semantic-sentences, closely parallels that between the two kinds of ellipsis discussed above. This is very far from a coincidence.)

Finally, one might divide up expressions into those which can be, and those

22 See Wittgenstein (1953) and Dummett (1981 and 1973, p. 194). 
which cannot be, used on their own (i.e., unembedded in any larger structure) to perform a speech act. The former would then be called sentences pragmatic $_{\text {, }}$ while the latter would be non-sentences pragmatic .

Given this three-fold division, let us first address the WittgensteinDummett dictum. It's perfectly true that only sentences pragmatic can be used in isolation. Indeed, it's tautological. So, read as a claim about sentences pragmatic $_{\text {, }}$ the dictum is on solid ground. We are not therefore insisting otherwise. Instead, what we're committed to is that non-sentences syntactic $_{\text {and non-sen- }}$ tences $_{\text {semantic }}$ can be used, unembedded, to perform speech acts. And, of course, it would be a fallacy of equivocation to infer from 'Sentences pragmatic $_{\text {are the }}$ only things which can be used and understood in isolation' to the conclusion that only sentences in either of the other two senses can be so used.

Our view, put another way, is that ordinary words and phrases, with both

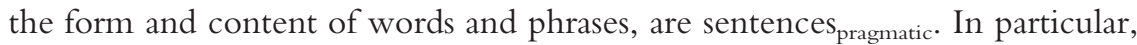
words and phrases can be used on their own to communicate thoughts, including premises in arguments. Since words and phrases just are sentences pragmatic $_{\text {, }}$ nothing we say conflicts with the truism that only sentences pragmatic $_{\text {can }}$ be used. But, crucially, we deny that this shows that the things communicated

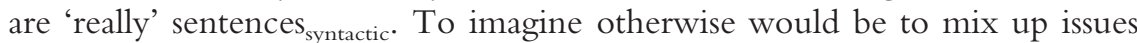
about the content that the speaker conveyed with issues about linguistic form. (It would, in fact, be on a par with a use-mention confusion: Alice meant $p$, therefore Alice meant ' $p$ '.) Less obviously, that words and phrases can be used to communicate thoughts does not show that their tokens encode the thoughts thereby communicated. Especially when pragmatic mechanisms are independently available to bridge the gap between what the word/phrase means, in context, and what its speaker meant. (Compare: one can mean $\mathrm{NN}_{\mathrm{N}}$ that $\mathrm{Mr}$. X is an awful student, by tokening ' $\mathrm{Mr}$. $\mathrm{X}$ has neat handwriting and usually arrives on time for class'; but this clearly doesn't show that one-tacitly, elliptically, under one's breath as it were- produced an expression whose meaning in the language is MR. X IS AN AWFUL STUDENT.) Once the distinction in (12) is carefully made, then, we see no particular danger from the truism that 'only sentences may be used to make a move in the language game'. We accept this claim, on its truistic reading; nevertheless, we reject it as false, on empirical grounds, when read in terms of sentences syntactic $_{\text {or sentences }}$ semantic $_{\text {. }}$.

But, the objector will insist, isn't there something right about Frege's Context Principle? We concede that there is: To find what a word or phrase means, one must ask what the word's content 'joins with' in order to yield a Gedanke (thought). For example, to find the meaning of 'seven dogs', it is a mistake to look either for an associated mental image or for an object. Instead, the meaning of 'seven dogs' must be understood in terms of how its content combines with a predicate-meaning to yield a Gedanke. Talking this way does make Gedanke 'primary', in some sense. (Which, we suspect, is all Frege himself really cared about.) So be it. We are perfectly happy with that. What it doesn't do is guarantee that only certain syntactic forms (e.g. Inflectional Phrases) or 
linguistic items bearing a certain kind of content (e.g. items of semantic type $<\mathrm{t}>$ ), can be used in conversation. Nor does it guarantee- far from it! that only these linguistic items have logical form fundamentally. In which case, properly construed-i.e. construed as a claim about the role of Gedanke in determining word-meaning, rather than as a claim about sentences-there likely is no conflict between our view and Frege's Context Principle. But, so read, the Context Principle does not support Vernacularism.

We can sum up Part 2 as follows: If propositions-meant have logical forms, and if those logical forms are not derivative on the logical forms of natural language expressions, then Vernacularism is false. What we have tried to do to render this conditional of non-trivial interest. The conditional claim would be of only trivial interest if its antecedent were obviously false. But, we have suggested, given the use of ordinary words to communicate propositions, it is quite plausible that there are things-meant, which have logical forms, but which are not linguistic items. And it's also plausible that those things-meant have their logical forms fundamentally.

\section{Vernacularism Assumed: Incompleteness and Russell's Theory of Descriptions}

Recall the central aim of this paper: to argue that (1) below isn't obviously true, and to suggest why this is important.

1. Vernacularism: The view that logical forms are fundamentally assigned to expressions of natural language, and are only derivatively assigned to anything else: e.g. propositions, mental states, etc.

Part 1 of the paper was dedicated to explaining what Vernacularism amounts to. Part 2 argued that it isn't obviously true. In this final part, we will give one example — namely, recent discussions of Russell's Theory of Descriptions - of why this result is important. Our aim is to give an example in which Vernacularism plays an important role in certain discussions in the philosophy of language. The example will therefore help support our claim that Vernacularism is a significant philosophical view.

The example serves other purposes as well, however. First off, one might reasonably complain that it remains obscure just how a speaker manages to communicate a full-fledged proposition, with a logical form, on the basis of uttering a mere word or phrase. Specifically, one might wonder how Alice could have communicated a proposition, about the pen, using the word 'red'. Our response, in a nutshell, is this: a speaker may draw the hearer's attention to an object, 'get the hearer to think about that object', and then produce a word whose content can be predicated of the object. That, we say, is how Alice achieved her impressive result. A further role of the following example, then, is to clarify the nature of this kind of conversational move, and to drive 
home its ubiquity. In particular, we will come to see a clear difference between recovering a word and noticing a thing. But this time it will be in the context of much more familiar philosophical terrain. Here, then, is the example.

A certain criticism of Russell's Theory of Description assumes Vernacularism. It goes like this. Suppose that Jones points to a photograph of Frank Sinatra and assertively utters (13), to Smith:

\section{The man is a great singer.}

(We ignore, for present purposes, the fact that Sinatra is dead.) According to Russell's (1905) Theory of Descriptions, (13) is logically equivalent to (14):

14. There is exactly one man, and every man is a great singer.

This latter sentence entails, by conjunction simplification, that there is exactly one man. Since this is patently false, it seems that Jones' utterance of (13) must itself be false-completely independently of Sinatra's vocal prowess. Hence Russell's Theory of Descriptions is reduced to absurdity. Call this criticism, 'the Original Reductio' (Strawson (1950)).

A natural defense of Russell's theory is to contend that Jones' utterance is semantically equivalent to a completion of (15):

15. There is exactly one man who is $H$, and every man who is $H$ is a great singer.

The predicate, represented by the schema $\lceil$ who is $H\rceil$ in (15), is said to be fixed by the context in which the incomplete description, 'the man', is uttered. In our example, the instance of $\lceil$ who is $H\rceil$, is some salient, contextually relevant predicate that is uniquely true of Sinatra-a predicate that Jones implicitly meant when he uttered (13). (For example, the instance of $\lceil$ who is $\mathrm{H}$ - might be 'who is pictured in that photograph', where Jones points to Sinatra's photograph.) Taking 'who is pictured in that photograph' as the intended completing description, (13) is said to be true exactly if:

16. There is exactly one man who is pictured in that photograph and every man who is pictured in that photograph is a great singer.

By hypothesis, Frank Sinatra is the only man in the only indicated photograph. So, (13) is predicted to be true if Sinatra is a great singer. In brief, if (13) is properly translated as (15), and if (15) is completed as in (16), then Jones's utterance can come out true. The Original Reductio is diffused.

Some philosophers remain unconvinced and have presented what we'll call 'The Many Descriptions Objection' to show why this defense of Russell's theory fails, cf. Wettstein (1981). Relative to the context in which Jones 
uttered 'The man is a great singer', there are many equally salient descriptions which are uniquely true of Sinatra and which are mutually known to be so by Jones and Smith. Here is a partial list:

\section{Salient Descriptions of Sinatra}

a. The skinny crooner who was the idol of many bobby-soxers during the early 1940s.

b. The guy who headed Hollywood's notorious 'Rat Pack' during the early 1960s.

c. The actor who won an Oscar for his supporting role in From Here to Eternity.

None of the listed descriptions of Sinatra is sufficiently salient for Smith to identify it as the one that Jones tacitly meant by his utterance of (13). Nothing about the context fixes for the hearer, among these many equally good candidate-descriptions, 'the one' that Jones had in mind at the time of the utterance. In fact, it isn't really necessary that there be a particular one that Jones meant (tacitly or otherwise). Thus even Jones himself might be at loss to specify 'the' description of Sinatra he meant. (For more on this, see Bach (1987), Elugardo (1997), Neale (1990), Reimer (1992), and Schiffer (1995).)

Suppose, then - to mount The Revised Reductio-that Vernacularism and the neo-Russellian view of incomplete definite descriptions are correct. Then, Jones will have meant a proposition that has a logical form only if he meant a proposition whose logical form is derivative on the logical form of a specific natural language sentence, a sentence whose (potential) utterance is a completion of (15):

15. There is exactly one man who is $H$, and every man who is $H$ was a great singer.

However, that general condition will not be met because, by hypothesis, there is no unique, contextually salient, completing description of Sinatra that Jones had in mind when he uttered (13). So runs the Many Descriptions Objection. Put otherwise, without a specific instance to take the place of $\lceil$ who is $H\rceil$ there is no sentence available from which to derive a logical form for the specific proposition asserted. Without that, there can be no proposition which is meant and which also has a logical form. (This last step is the one that employs Vernacularism.) Ergo, on this neo-Russellian line, if Vernacularism is true, then no logical-form-bearing proposition is meant. But that is absurd: patently, Jones did mean a proposition, and it did have a logical form. In particular, he communicated a proposition whose truth depends upon the vocal powers of Frank Sinatra. Furthermore, he meant something which, in this context, entitles Smith to use as a premise in an inference that Frank Sinatra was a vocalist; in which case, Jones meant something which has a logical 
form. So Russell's view is reduced to absurdity once again if Vernacularism is true.

The neo-Russellian might respond to the Many Descriptions Objection by saying that Jones didn't really mean any particular proposition. But this really isn't plausible. What gives the objection its force is the hard-to-deny intuition that Jones meant just one thing by his utterance of 'The man was a great singer'. The idea that he vaguely meant indefinitely many, extensionally equivalent, descriptive propositions by his utterance is a bit too much to accept. If anything, that would give one some reason to think that maybe Jones really didn't mean anything at all by his utterance, but certainly that is unacceptable.

Given that, one might try to save Russell, while holding onto Vernacularism, by saying that Jones didn't assert any proposition made-true by Sinatra, though Jones did mean something by his utterance. What he asserted, runs this defense, was a metalinguistic existential proposition-something like:

18. There exists some description $d$ such that when $d$ is substituted for the variable in 'There is exactly one man who is $H$, and every man who is $H$ was a great singer' the result is a true sentence.

But this won't do either. For if that was what Jones really said, it is hard to see how he managed to convey a proposition whose truth-maker is Sinatra and his singing abilities - something he unquestionably managed to do. (18) is far too weak if $d$ is in no way circumscribed. The reason being that, after all, every adult human male is such that there is a description of him which, when substituted into (15), yields a truth! In which case, (18) clearly will not allow the hearer to draw any reasonable inference about what sort of adult male is being discussed. In particular, it won't allow the hearer to figure out that Jones is referring to Sinatra. On the other hand, once one tries to circumscribe $d$, the previously noted problem arises in a slightly different guise: nothing about the context fixes, among the many candidate circumscriptions-of- $d$, the one that Jones had in mind at the time of the utterance.

The upshot so far is this. The neo-Russellian view apparently requires that Jones and his interlocutor have a description in mind. Without that, either there is no sentence from which the proposition-meant can get its logical formwhich would entail, given Vernacularism, that there is no logical-form-bearing proposition at all-or the sentence is merely metalinguistically existential, as in (18) - which leaves the hearer at a loss to figure out what Jones is on about. But there's a nagging problem: though the Russellian approach demands one, there actually is no such description.

Our real point, in the end, is that The Revised Reductio of Russell's Theory presupposes Vernacularism. The reductio implicitly contains the premise that the lack of a predicate, to be substituted for $\lceil$ who is $H\rceil$, entails that there cannot be an appropriate proposition meant. But if propositions can have logical forms, without there being a sentence that 'provides' or 'endows' that 
logical form, then Jones could mean such a proposition, even though no sentence is available to him or to his hearer, which expresses the proposition. Roughly put, Jones could intend a restricted set of adult males, and Smith could guess what set Jones intended, without Smith or Jones fixing on an English predicate that encodes the restriction.

We still have not explained precisely how this might go, however. Nor is this an idle issue. For, it might reasonably be said, if arguments against Russell's Theory of Descriptions can be straightforwardly reconstructed, without appeal to a many descriptions objection, then it won't be obvious why it matters so much whether Vernacularism is true. Our aim at this point, then, to put it another way, is to show that Vernacularism isn't just a suppressed premise in the argument discussed, but an important (i.e. not easily dispensable) suppressed premise.

We will therefore attempt to say rather more about how neo-Russellians might defend themselves. We want to stress, however, that in discussing this, we don't wish to commit ourselves to either view.

The first step, in answering the proposed reductio, would be to reconstruct the defense of Russell as follows. What (13) amounts to is not (15), but simply (14):

13. The man is a great singer.

14. There is exactly one man, and every man is a great singer.

15. There is exactly one man who is $H$, and every man who is $H$ is a great singer.

However, despite initial appearances, literal utterances of (15) can easily be true. The reason is, whenever (14) is uttered, there is an intended domain of quantification. And, sometimes, that domain of quantification contains just one man. ${ }^{23}$ The same will therefore hold, given Russell's Theory, for (13). Crucially, however, the intended domain of quantification can be determinate even if there is no salient predicate that has the domain as its extension. Specifically, the domain of quantification can itself be salient-because it is (or its elements are) easily perceptible in the environment. (Compare a lesson we take from Gareth Evans: someone can see an object in the distance, without tokening a natural language description of the object-not even 'object which I see in the distance'. What makes the person's thought be about that object? Not, says Evans, some purported linguistic description of it; instead, it is because that is the object she is perceiving.) Looked at this way, a set itselfrather than a linguistic description of it-is salient in the environment because, for example, it (or its elements) is perceptible. Taking this set to be the domain

23 We stipulate, for the purposes of simplifying discussion, that it is Sinatra himself, and not just the photograph of Sinatra, who is salient. 
of quantification, (14) can turn out true. So, one cannot then use the 'obvious falsehood of (14)' to produce a reductio of Russell's Theory.

Here is another way of making the same point - a way which helps to further clarify the difference between recovering a word and noticing a thing. Stephen Neale distinguishes an 'explicit' and an 'implicit' approach to incomplete quantifiers. ${ }^{24} \mathrm{He}$ writes:

There are two main approaches to incompleteness in the literature, what we might call the explicit and the implicit approaches. According to the explicit approach, incomplete quantifiers are elliptical for proper quantifiers. As Sellars puts it, the descriptive content is 'completed' by context. According to the implicit approach, the context of utterance delimits the domain of quantification and leaves the descriptive content untouched. Consider [the sentence 'Everybody was sick'] again. On the explicit approach, the quantifier 'everybody' (as it is used on this occasion) is elliptical for 'everybody at the dinner party I had last night', or some such 'narrower' quantifier. On the implicit approach, the domain of quantification is understood as restricted to some favored class of individuals (or to some favored part of the world) (Neale 1990, p. 95).

The explicit approach really does demand, in order to 'narrow down' a definite description like 'the man', that some completing linguistic description be found: e.g. the phrase 'in that photograph'. That is, the explicit approach is as much committed to Vernacularism as the critic who puts forward the Many Descriptions Objection. But the implicit approach is crucially different. ${ }^{25}$ (And, in fact, it's a close cousin of our story about how ordinary words and phrases are understood in conversation.) Assuming Vernacularism isn't true-so it is possible to contextually restrict the domain of quantification by means of something other than a description - the implicit approach remains on solid footing, even if no unique description can be found.

We can draw two lessons from this entire discussion. First, once Vernacularism is explicitly noticed, and once its falsehood becomes a real possibility, extra elbow room opens up in the philosophy of language. Options not previously explored suggest themselves. In the case at hand, the idea that domain of quantification can be grasped without the hearer settling on a description makes the Russellian committed to less than what one might suppose. Specifi-

24 This topic is revisited in Neale (2000), which responds to Stanley and Szabo (2000). See also Bach (2000).

25 This highlights the fact, stressed by Reimer (1998, p. 106ff), that the two approaches are not 'notational variants' of one another. To put it in terms introduced above: whereas the explicit approach involves ellipsis, or anyway the recovery of the part of the hearer of some unpronounced linguistic item, the implicit approach requires instead that the hearer notice a salient non-linguistic something. 
cally, she needn't be committed to the implausible claim that there is always a single salient linguistic description, to complete the description used-as some critics have supposed. This is one respect, then, in which it is important that Vernacularism may not actually be true. (What's more, this is far from an isolated example of Vernacularism being assumed by some, but not all, on both sides in the debate. ${ }^{26}$ But space doesn't permit describing others.)

The second lesson is less direct. It is reasonable to wonder just how logical form bearing non-linguistic things can be communicated, by using plain old words and phrases. Reflection on incomplete descriptions provides rather more than a clue, within a much more familiar domain. In discussing Russell's Theory of Descriptions, we saw how a set of objects can be salient, so that this set can be the domain of quantification. Such saliency did not require that the speaker intend, or the hearer recover, a linguistic description of the set. ${ }^{27}$ In much the same way, a single object can be salient, not because the speaker covertly, elliptically, etc., produced a description of it, and not because the hearer recovered some description of it, whether used or not, but because that object is presently in the environment of both the speaker and hearer. Once the object itself is salient, there is nothing to stop the hearer from grasping a proposition with a logical form: a proposition that contains the object as one constituent and, say, the property red as the other, where the property-element of the proposition is brought to her attention by a speaker's production of an ordinary word or phrase that expresses that property. This, we believe, is precisely how non-sentential communication works.

To conclude: we have explained what Vernacularism says, and we have argued, on the basis of non-sentential speech within arguments, that it may well be false. The reason provided was that speakers can communicate propositions, which can be used as premises, by producing ordinary words and phrases. What they thereby communicate are not themselves linguistic items; but they nevertheless have logical forms. We further argued that, in at least one case (and, we believe, in very many more), it is implausible to suppose that the thing-meant gets assigned a logical form on the basis of recovering a linguistic item that encodes the thing-meant. So not only are there nonlinguistic things which have logical forms, but some of them have their logical

26 Clearly, Russellians who adopt the explicit approach in their semantic analysis of incomplete definite descriptions assume Vernacularism. Interestingly, some critics of that approach also assume Vernacularism, e.g. Schiffer (1995) and Wettstein (1981). On their view, the speaker of a referential utterance of a sentence of the form, 'the $F$ is $G$ ', where 'the $F$ ' is an incomplete definite description, means an object-dependent proposition, one whose logical form is derivative upon the logical form of the very sentence that the speaker uttered-it is just that, on their view, the logical form of a referentially used descriptive sentence is that of an indexical sentence. Other critics of the explicit approach reject that version of Vernacularism as well, e.g. Recanati (1997), Sperber and Wilson (1981, pp. 191-193).

27 In Reimer (1998), Marga Reimer argues that contextually salient properties can delimit the intended domain of quantification for referential utterances of the form, 'The $F$ is $G$ '. 
forms fundamentally. Or so it seems. We ended by looking at a case, discussions of incompleteness and Russell's Theory of Descriptions, in which both parties in the dispute had assumed Vernacularism. It became clear that, once Vernacularism was rejected, the Russellian could tell a more plausible story. One reason why the falsehood of Vernacularism is important is precisely that it is, here and elsewhere, assumed as a suppressed premise: a suppressed premise, indeed, which can blind one to more plausible treatments. Our overall conclusion, then, is that Vernacularism may well be false, and that it's rather important if it is.

\author{
Department of Philosophy \\ University of Oklahoma \\ Department of Philosophy \\ Carleton University, Ottawa
}

\title{
References
}

Bach, K. 1987: Thought and Reference. Oxford University Press.

Bach, K. 2000: Quantification, qualification and context: a reply to Stanley and Szabo. Mind \& Language 15, 262-283.

Barber, A. 1998: The pleonasticity of talk about concepts. Philosophical Studies, 89, 56-86.

Barber, A. 1997: Deflated concepts: a reply to Stainton. Critica, 29, 83-105.

Bar-On, D. 1994: Conceptual relativism and translation. In G. Preyer, et al. (eds.), Language, Mind and Epistemology. Dordrecht: Kluwers, 145-170.

Barton, E. 1991: Nonsentential constituents and theories of phrase structure. In K. Leffel and D. Bouchard (eds.), Views on Phrase Structure. Dordrecht: Kluwer.

Carnap, R. 1967: Meaning and Necessity. Chicago: University of Chicago Press.

Carruthers, P. 1998: Thinking in language? Evolution and a modularist possibility. In P. Carruthers and J. Boucher (eds.), Language and Thought: Interdisciplinary Themes. Cambridge University Press, 94-119.

Carruthers, P. 1996: Language, Thought, and Consciousness: An Essay in Philosophical Psychology. Cambridge University Press.

Davidson, D. 1975: Thought and talk. In S. Guttenplan (ed.), Mind and Language. Oxford University Press. Reprinted in Inquiries into Truth \& Interpretation. Oxford University Press, 1984, 155-170.

Dummett, M. 1981: The Interpretation of Frege's Philosophy. London: Duckworth.

Dummett, M. 1973: Frege: Philosophy of Language. Cambridge, MA: Harvard University Press.

Elugardo, R. 1997: Descriptions, indexicals and speaker meaning. Protosociology, 10, 155-189.

(C) Blackwell Publishers Ltd. 2001 
Evans, G. 1976: Semantic structure and logical form. In G. Evans and J. McDowell (eds.), Truth and Meaning: Essays in Semantics. Oxford University Press, 199-222.

Fodor, J. 1978: Propositional attitudes. The Monist, 61, 501-523.

Fodor, J. 1975: The Language of Thought. New York: Crowell.

Frege, G. 1884: The Foundations of Arithmetic. Trans. J.L. Austin. Oxford: Blackwell.

Geach, P. 1957: Mental Acts. London: Routledge and Kegan Paul.

Grice, H.P. 1989: Studies in the Ways of Words. Cambridge, MA: Harvard University Press.

Katz, J.J. 1981: Language and Other Abstract Objects. Oxford: Blackwell.

May, R. 1991: Linguistic theory and the naturalist approach to semantics. In D.J. Napoli and J. Kegl (eds.), Bridges Between Psychology and Linguistics: A Swarthmore Festschrisft for Lila Gleitman. Hillsdale: Lawrence Erlbaum Associates, 269-288.

McDowell, J. 1994: Mind and World. Cambridge, MA: Harvard University Press.

Moravcsik, J.M. 1998: Meaning, Creativity, and the Partial Inscrutability of the Human Mind. Stanford: CSLI Publications.

Neale, S. 1990: Descriptions. Cambridge, MA: MIT Press.

Neale, S. 2000: On being explicit: comments on Stanley and Szabo, and on Bach. Mind \& Language, 15, 284-294.

Quine, W.V.O. 1979: Intensions revisited. In P. French, et al. (eds.), Contemporary Perspectives in the Philosophy of Language. Minneapolis: University of Minnesota Press, 268-274.

Recanati, F. 1997: Direct Reference: From Language to Thought. Oxford: Blackwell.

Reimer, M. 1998: Quantification and context. Linguistics and Philosophy, 21, 95-115.

Reimer, M. 1992: Incomplete descriptions. Erkenntnis, 37, 347-363.

Russell, B. 1905: On denoting. Mind, 14, 479-493.

Schiffer, S. 1997: Meanings and concepts. New York University, ms.

Schiffer, S. 1996: Language-created, language independent entities. Philosophical Topics, 24, 149-167.

Schiffer, S. 1995: Descriptions, indexicals, and belief reports: some dilemmas (but not the ones you expect). Mind, 104, 107-131.

Schiffer, S. 1994: A paradox of meaning. Nous, 28, 279-324.

Sellars, W. 1963: Some reflections on language games. In his Science, Perception, and Reality. London: Routledge and Kegan Paul, 321-358.

Sperber, D. and Wilson, D. 1998: The mapping between the mental and the public lexicon. In P. Carruthers and J. Boucher (eds.), Language and Thought: Interdisciplinary Themes. Cambridge University Press, 184-200.

Sperber, D. and Wilson, D. 1986: Relevance: Communication and Cognition. Cambridge, MA: Harvard University Press.

Stainton, R.J. 1999: Interrogatives and sets of answers. Forthcoming in Critica.

Stainton, R.J. 1998: Quantifier phrases, meaningfulness 'in isolation' and ellipsis. Linguistics and Philosophy, 21, 311-340.

Stainton, R.J. 1997: Utterance meaning and syntactic ellipsis. Pragmatics and Cognition, $5,49-76$. 
Stainton, R.J. 1995: Non-sentential assertions and semantic ellipsis. Linguistics and Philosophy, 18, 281-296.

Stainton, R.J. 1994: Using non-sentences: an application of relevance theory. Pragmatics and Cognition, 2(2), 269-284.

Stainton, R.J. 1989/92: Discourse in a Bilingual Setting: Working Papers at LE CAMP. Two volumes. Toronto: Applied Linguistics Research Working Group (ALRWG), Glendon College of York University.

Stainton, R.J. 1990/91: A LE CAMP Sourcebook. Two volumes. Toronto: Applied Linguistics Research Working Group (ALRWG), Glendon College of York University.

Stanley, J. and Szabo, Z.G. 2000: On quantifier domain restriction. Mind \& Language, 15, 219-261.

Strawson, P. 1950: On referring. Mind, 59, 320-344.

Wettstein, H. 1981: Demonstrative reference and definite descriptions. Philosophical Studies, 40, 241-257.

Wittgenstein, L. 1953: Philosophical Investigations. Oxford: Basil Blackwell. 